\title{
Zayıf Kayaçlarda Makinalı Kazı Performansının Kestirilmesindeki Zorluklar
}

\author{
Difficulty on Performance Prediction of Excavation with Machine in Weak Rocks
}

Evren POŞLUK ${ }^{1} \mathbb{D}$, Mustafa KORKANÇ ${ }^{2} \mathbb{D}$

${ }^{1}$ TCDD 2. Demiryolu Yapım Grup Müdürlüğü, Bozüyük, Bilecik, Türkiye

${ }^{2}$ Niğde Ömer Halisdemir Üniversitesi Mühendislik Fakültesi Jeoloji Mühendisliği Bölümü, Niğde, Türkiye

\section{Geliş (Received): 04 Aralık (December) 2017 / Düzeltme (Revised): 12 Nisan (April) 2018 / Kabul (Accepted): 12 Haziran (June) 2018}

\section{ÖZ}

Kayaç kütle sınıflama sistemleri birçok madencilik ve mühendislik uygulamalarının ön aşamalarında, kayaç tanımlaması ve tasarım amacıyla kullanılmaktadır. Proje ve tasarım aşamasında tünel delme makinesi (TBM) performans tahmini için teorik ve deneysel yöntemler bulunmaktadır. Makine performansının doğru tahmini çok sayıda kaya kütlesi parametresinin göz önünde tutulmasını gerektirir. Homojen ve izotrop kaya ortamlarında makine performansını öngörmek nispeten kolay olsa da, zayıf ve anizotrop kaya ortamlarında makine performansının kestirimi oldukça zordur. TBM performansının tahmini konusunda günümüze kadar yapılan birçok araştırma, penetrasyon ve kaya kütlesi sınıflamaları arasında zayıf bir ilişki olduğunu ortaya koymaktadır. Bu çalışmada, Ankara-İstanbul yüksek hızlı tren projesinde yer alan 26 numaralı (Bilecik İli ile Bozüyük İlçesi arasında) tünelde kullanılan TBM'in $\mathrm{Q}_{\text {твм }}$ yöntemi ile anizotrop zayıf kaya için yapılan performans analizi sunulmuştur. Değerlendirme makinenin tünel içerisinde sıkışmasına kadar geçen kesimi kapsamaktadır. Çalışma sonucunda, $\mathrm{Q}_{\mathrm{TBM}}$ yönteminde anizotrop zayıf kayada uygulama problemleriyle karşılaşıldığı, benzer ortamlarda kesici disk değişim zaman aralığı tahminin son derece zor olduğu ve bu nedenle de performans kestirimi için kaya kütlesinin anizotropik özellikleri ile makine özelliklerinin ilişkilendirilerek katılmasının gerektiği sonucuna varılmıştır.

Anahtar Kelimeler: Anizotropi, İlerleme hızı, $\mathrm{Q}_{\mathrm{TBM}}$, TBM performansı, Tünel, Zayıf kaya

\section{ABSTRACT}

Rock mass classification systems are used for rock mass characterization and design in the preliminary stages of many mining activities and engineering applications. There are theoretical and experimental methods for the prediction of tunnel boring machine (TBM) performance in project stage. The correct estimation of machine performance is influenced by many input parameters of rock mass, and although it is relatively easy to predict machine performance in isotropic intact rock environments, it is very difficult in poor rock having anisotropic behaviour. Many studies in this area have shown a poor relationship with penetration and rock mass classifications. In this study, the performance analysis of TBM in anisotropic weak rock environment with the $Q_{T B M}$ method, which is used in the Tunnel No. 26 (between Bilecik and Bozuyuk), located in the Ankara-İstanbul high-speed train line, has been examined in the section until the machine is trapped in the tunnel. It is concluded that there exist problems for the anisotropic weak rocks in the $Q_{T B M}$ method. It is extremely difficult to estimate the intermittent disk change time interval in such environments, and the relationship between properties of anisotropic rock mass and machine characteristics should be considered together for the performance machine prediction.

Keywords: Anisotropy, Advance rate, $Q_{T B M}$ TBM performance, Tunnel, Weak rock 


\section{GİRIŞ}

Uzun tünel imalatlarında (sağlam kayada $>2000 \mathrm{~m}$ ) diğer yöntemlere göre maliyet ve süre açısından önemli avantajlar sağlayan tam çeperli tünel açma makineleri (TBM) tercih edilmektedir. TBM performans analizi, tünel tasarımında, kazı planlamasında ve makine seçiminde önemli bir aşamadır (Salimi vd., 2016). Performans analizinin yanlış tahmini büyük zaman ve maliyet artışlarına neden olmaktadır.

TBM'nin performansı ve kullanımı, tünel boyunca karşılaşılan kaya kütlesi koşulları, çalışma parametreleri ve makine özellikleri olarak sıralanabilen birçok etmene bağlıdır. Hangi etmenlerin TBM performans1 üzerinde belirgin bir etkiye sahip olduğunu belirlemek oldukça karmaşıktır (Frough vd., 2015). Makinedeki veya geçilen jeolojik birimlerdeki küçük değişiklikler bile makine performansı üzerinde önemli bir etkiye sahip olmaktadır. Değişken kaya kütlesi koşullarında TBM performansının doğru bir şekilde tahmin edilmesi oldukça zor bir durumdur.

Son yıllarda TBM'lerin değerlendirilmesi için sayısız TBM performans tahmin modeli ve düzeltme faktörleri önerilmiştir. Bu yöntemler teorik ve deneysel olmak üzere iki yaklaşıma ayrilabilir (Rostami vd., 1996). Teorik modeller, kesici disk üzerine etki eden kesme kuvvetlerini, kuvvet denge eşitliklerini bulmak için analiz gerçekleştirirken, ampirik modeller TBM'lerin saha performansinın gözlemlenmesine dayanmaktadır (Çizelge 1).

Önerilen yöntemlerden, bu çalışmanın da temel dayanak noktasını oluşturan, $\mathrm{Q}_{\mathrm{TBM}}$ yöntemi 2000 y1lında Barton tarafindan önerilmiştir. Barton (2000), bu modelde, kaya kütlesi sınıflandırması için orijinal Q sistemini TBM nüfuz etme oranını (anlık ilerleme-PR) ve gerçek ilerleme hızını (günlük ilerlemeAR) tahmin etmeyi sağlayan yeni bir $Q_{T B M}$ sistemine genişletmiştir. Sistem, ortalama kesme kuvvetini, kayanın aşındırıcı doğasını, tünel derinliğindeki gerilme alanını ve kesici disklerin değişimini kestirmek için önerilmiştir (Çizelge 1). $Q_{\text {твм }}$ esas olarak, deneyimli bir mühendislik jeologu ve maden mühendisi tarafından basitçe tahmin edilebilen temel jeolojik ve jeoteknik parametrelere dayanmaktadır (Sapigni vd., 2002). Metodun ana düşüncesi, TBM ilerleyişi için son derece iyi $(400 \leq \mathrm{Q} \leq 1000)$ ve aşırı kötü koşulların $(0.01 \leq \mathrm{Q} \leq 0.001)$ olumsuz olduğunu dikkate almaktır. Özellikle ilk durumda, kesici takımlar için bakım sürelerinin artması nedeniyle daha düşük bir nüfuz etme oranı gözlemlenebilmektedir. İkinci durumdaki engel ise daha ağır desteklemeye gereksinim duyulması ve kaya stabilitesinin arttırılması için enjeksiyon çözümlerine ihtiyaç duyulmasıdır. $\mathrm{Bu}$ da beraberinde makinenin daha uzun duraksamasına neden olmaktadır. Bu kaygılardan hareketle Barton (2000), kaya kütlesi kalitesinin fonksiyonları olarak değerlendirilen nüfuz etme oranı (PR), sürekli delme süreci ve gerçek ilerleme hızı (AR) için genel eşitlikler önermiştir.

Bu çalışmada oldukça karmaşık bir jeolojiye sahip Ankara-İstanbul Hizlı Tren Projesi, Bilecik ile Bozüyük arasında yeralan bölgede açılan 26 numaralı tünelde, $\mathrm{Q}_{\mathrm{TBM}}$ yönteminin 
Çizelge 1. TBM performans modelleri.

Table 1. Models of the TBM performance.

\begin{tabular}{|c|c|c|c|}
\hline Referanslar & Metod & Kaya Parametreleri & Makine Parametreleri \\
\hline Tarkov (1973) & Ampirik & Sağlam kaya sertliği & Kesici disk kuvveti \\
\hline $\begin{array}{l}\text { Roxborough ve Phillips } \\
\text { (1975) }\end{array}$ & Teorik/Deneysel & Sağlam kaya sertliği & Kesici disk kuvveti \\
\hline Graham (1976) & Ampirik & Tek eksenli basınç dayanımı & Kesici disk kuvveti \\
\hline Ozdemir vd. (1977) & Teorik/Deneysel & Tek eksenli basınç dayanımı & Kesici disk kuvveti \\
\hline Farmer ve Glossop (1980) & Ampirik & Brezilya indirekt çekme dayanımı & Kesici disk kuvveti \\
\hline Snowdou vd. (1982) & Teorik/Deneysel & Sağlam kaya sertliği & Kesici disk kuvveti \\
\hline Büchi (1984) & Teorik/Deneysel & $\begin{array}{l}\text { Basınç ve çekme dayanımı, kaya } \\
\text { anizotropisinde düzeltme faktörleri, } \\
\text { çatlak aralığı, kayanın mika içeriği }\end{array}$ & $\begin{array}{l}\text { Kesici aralığı, kesici uç genişliği, kesici } \\
\text { yarıçapı, kesici kuvvet, TBM çapı, } \\
\text { kesici disk sayısı }\end{array}$ \\
\hline Sanio (1985) & Teorik/Deneysel & Sağlam kaya sertliği & Kesici disk kuvveti \\
\hline Hughes (1986) & Teorik/Deneysel & Tek eksenli basınç dayanımı & Kesici disk kuvveti, Fn, kesici disk çapı \\
\hline Sato vd. (1991) & Teorik/Deneysel & Sağlam kaya sertliği & Kesici disk kuvveti \\
\hline Innaurato vd. (1991) & Ampirik & Kaya yapısı derecelendirmesi (RSR) & Kesici disk kuvveti \\
\hline Rostami ve Ozdemir (1993) & Teorik/Deneysel & $\begin{array}{l}\text { Tek eksenli basınç, Brezilyan } \\
\text { indirekt çekme dayanımı, Cherchar } \\
\text { aşındırma endeksi }\end{array}$ & Kesici disk kuvveti, kesici uç genişliği, \\
\hline Palmstrom (1995) & Ampirik & Kaya kütle indeksi (RMI) & Kesici disk kuvveti \\
\hline Bruland (1998) & Ampirik & $\begin{array}{l}\text { Tek eksenli basınç, sondaj oranı } \\
\text { endeksi (DR1), eklem set sayıs1, } \\
\text { eklem yönlendirmesi, porozite }\end{array}$ & $\begin{array}{l}\text { Kesici disk kuvveti, kesici kafa devir } \\
\text { hızı, kesici boyutu ve şekli, itki kuvveti }\end{array}$ \\
\hline Barton (2000) & Ampirik & $\begin{array}{l}\text { Q sistemi parametreleri, kesici ömrü } \\
\text { endeksi (CLI), kuvars içeriği, iki } \\
\text { eksenli gerilme, porozite }\end{array}$ & Kesici disk kuvveti \\
\hline Yağiz (2002) & Teorik/Deneysel & $\begin{array}{l}\text { Tepe eğimi indeksi (PSI), zayıf } \\
\text { nokta düzlemi arasındaki mesafe } \\
\text { (DPW), Cherchar aşındırma endeksi } \\
\text { (CAI) }\end{array}$ & Kesici disk kuvveti \\
\hline Bieniawski vd. (2007) & Ampirik & $\begin{array}{l}\text { Modifiye edilmiş RMR sistemi } \\
\text { parametreleri }\end{array}$ & $\begin{array}{l}\text { Makine çap1, toplam kesici kafa gücü, } \\
\text { tork }\end{array}$ \\
\hline Yağiz (2008) & Ampirik & $\begin{array}{l}\text { Tek eksenli basınç dayanımı, } \\
\text { kırılganlık indeksi }\end{array}$ & Kesici disk kuvveti \\
\hline Hassanpour vd. (2009) & Ampirik & Tek eksenli basınç dayanımı, RQD & $\begin{array}{l}\text { Kesici disk kuvveti, kesici kafa devir } \\
\text { hızı }\end{array}$ \\
\hline Gong ve Zhao (2009) & Ampirik & $\begin{array}{l}\text { Basınç dayanımı, hacimsel eklem } \\
\text { sayısı, gevreklik indeksi, ana } \\
\text { süreksizlikler ile tünel ekseni } \\
\text { arasındaki açı }\end{array}$ & Kesici disk kuvveti \\
\hline Delisio ve Zhao (2014) & Ampirik & $\begin{array}{l}\text { Tek eksenli basınç dayanımı, } \\
\text { hacimsel eklem sayısı }\end{array}$ & İtki kuvveti, kesici kafa devir hızı \\
\hline Benato ve Oreste (2015) & Ampirik & Tek eksenli basınç dayanımı, GSI & Kesici disk sayıs1 \\
\hline
\end{tabular}


uygulanabilirliğinin araştırılması amaçlanmıştır. Bu amaçla, $13.77 \mathrm{~m}$ çapındaki tek kalkanlı TBM için tünel girişinden makinanın tünel içerisinde sıkışmasına kadar geçen kesimde hesaplanan (öngörülen) ile tünelde gerçekleşen ilerlemelerin karşılaştırmaları yapılmıştır.

\section{MATERYAL VE YÖNTEM}

26 numaralı tünel, Ankara-İstanbul hızlı tren projesinde Bilecik ilinin $10 \mathrm{~km}$ güney doğusunda, Ahmetpınar Köyü'nün 200 m batısında bulunmaktadır. Tünel güzergâhının batısında Bozüyük-Mekece karayolu ve bölge morfolojisini oluşturan Karasu Deresi bulunmaktadır. Tüneldeki örtü kalınlığı 30-236 $\mathrm{m}$ arasında değişim göstermektedir.

\section{$Q_{\text {твм }}$ yöntemi}

Bu yöntem, Barton vd. (1974) tarafindan önerilen Q sisteminin TBM performansı için geliştirilen versiyonudur. $\mathrm{Bu}$ sistemin temel amacı kaya kütle sinıflama sistemi olarak kullanılan Q sisteminden yararlanarak TBM için anlık (PR) ve günlük (AR) ilerleme hızını hesaplamaktır.
Anlık (PR) ve günlük (AR) ilerleme hızı hesaplamaları için Barton (2000) tarafindan önerilen eşitlikler aşağıda verilmiştir;

$\operatorname{PR}($ Anlık ilerleme $)=P R=5 Q_{T B M}^{-1 / 5} \mathrm{~m} / \mathrm{saat}(1)$

$\mathrm{AR}($ Günlük ilerleme $)=P R x T^{m} \mathrm{~m} / \mathrm{saat}$,

$\mathrm{AR} \times 24 \mathrm{~m} /$ gün

$\mathrm{Bu}$ eşitlikte $\mathrm{T}$ süre olup, aşağıdaki eşitlikte (Eşitlik 3) belirlenir;

$T=\left(\frac{L}{P R}\right)^{\frac{1}{1+m}}$

$\mathrm{Bu}$ eşitlikte "L" tünelin uzunluğunu ifade etmektedir. " $\mathrm{m}$ " ise aşınmadan dolayı ilerleme azaltma faktörü olup, aşağıdaki eşitlikten hesaplanmaktadır.

$$
m=m_{1} x\left(\frac{D}{5}\right)^{0,20} x\left(\frac{20}{C L I}\right)^{0,15} x\left(\frac{q}{20}\right)^{0,10} x\left(\frac{n}{2}\right)^{0,05}
$$

Burada, " $\mathrm{m}_{1}$ " aşınmadan dolayı ilerleme azaltma faktörü başlangıç değeri olup, Şekil 1'den yararlanılarak elde edilir, "D" TBM kazı çapıdır, "n" ise kayacın porozite değerini göstermektedir (Barton, 2000).

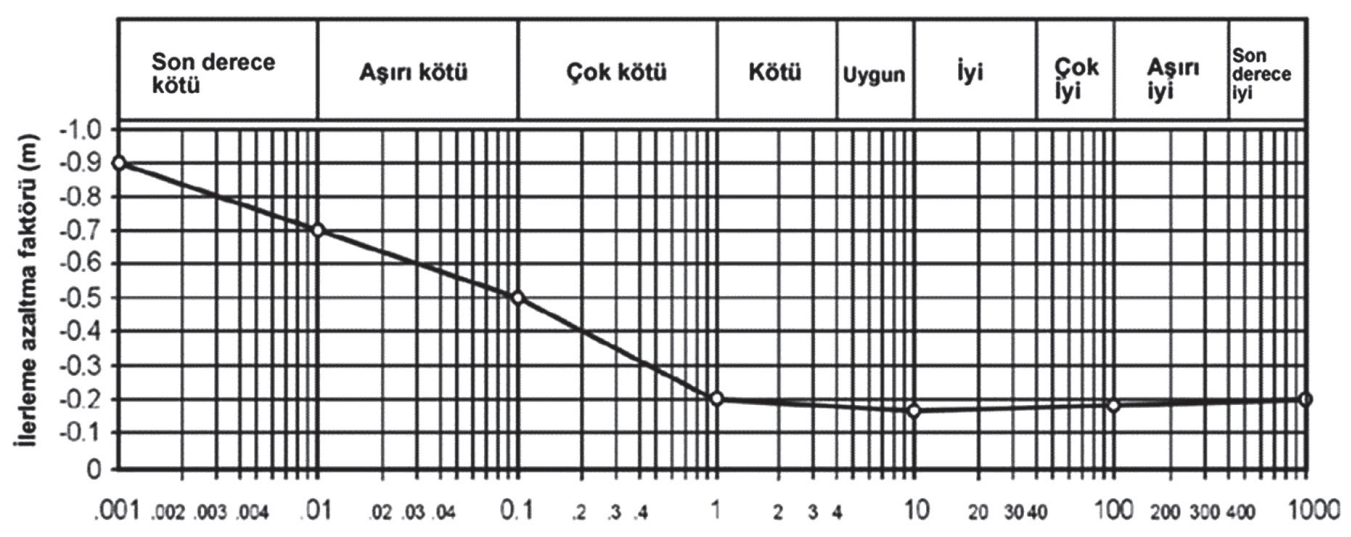

Şekil 1. Aşınmadan dolayı ilerleme azaltma faktörü başlangıç değerini (m) Q değerinin fonksiyonu olarak gösteren ilişki (Barton, 2000).

Figure 1. Preliminary estimate of declining advance rate gradient (m), as function of $Q$-value (Barton, 2000). 
Günlük ve anlık ilerleme hızı hesaplamaları için önerilen eşitliklerde kullanılan $\mathrm{Q}_{\mathrm{TBM}}$ değeri,

$Q_{T B M}=\left[\frac{\mathrm{RQDo}}{J n} \times \frac{J r}{J n} \times \frac{J w}{S R F} \times \frac{S I G M A}{F^{10} / 20^{9}} \times \frac{20}{C L I} \times \frac{q}{20} \times \frac{\sigma_{\theta}}{5}\right]$

eşitliğinden belirlenmiştir.

RQD o kavramı, yönlendirilmiş RQD için kullanılmaktadır. RQD değerinin sondajın tünel ekseni yönünde açılması durumundaki tahmini esasina dayanan bir parametredir). $\mathrm{J}_{\mathrm{n}}, \mathrm{J}_{\mathrm{r}}, \mathrm{J}_{\mathrm{a}}, \mathrm{J}_{\mathrm{w}}$ ve SRF ise Q siniflama sistem parametreleridir. F her bir kesiciye gelen itme kuvvetidir ve üretici firma verilerinden yararlanılmaktadır.

SIGMA kavramı, kaya kütle dayanımını belirtmek için kullanılmaktadır (Sing vd., 1992). Başka bir anlatımla kayacın dayanımını, birim hacim ağırlığı, tek eksenli basınç dayanımı $\left(\sigma_{c}\right)$, nokta yükü indeksi $\left(\mathrm{I}_{50}\right)$ ve süreksizlik düzlemleri ile tünel ekseni arasındaki açıyı ( $\beta$ ) (Şekil 2) dikkate alarak açıklamaya çalışan parametredir (Maidl vd., 2008).

$$
\begin{aligned}
& \operatorname{SIGMA}=\operatorname{SIGMA}_{\mathrm{cm}}=\ldots \ldots \ldots \ldots \ldots \beta>60^{\circ} \\
& \mathrm{SIGMA}=\operatorname{SIGMA}_{\mathrm{tm}}=\ldots \ldots \ldots \ldots \ldots \beta 30^{\circ}
\end{aligned}
$$

CLI (Kesici disk ömrü) ise, kesici kafada bulunan kesici disklerin aşınmadan kaynaklı periyodik değişimlerini ifade etmektedir. $\mathrm{Bu}$ durum, genellikle seçilen kesicilere ve masif kayanın fiziksel ve mekanik özelliklerine bağlıdır. $\mathrm{Bu}$ nedenle, kesici disklerin değiştirilmesi, vardiya değişimi, makine bakımı vs. gibi farklı nedenlerden dolayı doğan duraklamalara "utilization" (U) denmektedir ve klasik TBM kazılarında günlük ilerlemenin bir fonksiyonu olarak aşağıdaki şekilde hesaplanmaktadır.

$\mathrm{AR}=\mathrm{UxPR}$

Fakat Nelson (1993), PR ve U için ayrı ayrı kaya kütle sınıflaması ile ilişkilendirmiştir. Kesici ömrü tahmini için Movinkel ve Johannessen (1986)'nın ayrıntılı çalışmalar sonucunda belli başlı kaya türleri için önerdikleri abak kullanılmaktadır (Şekil 3).

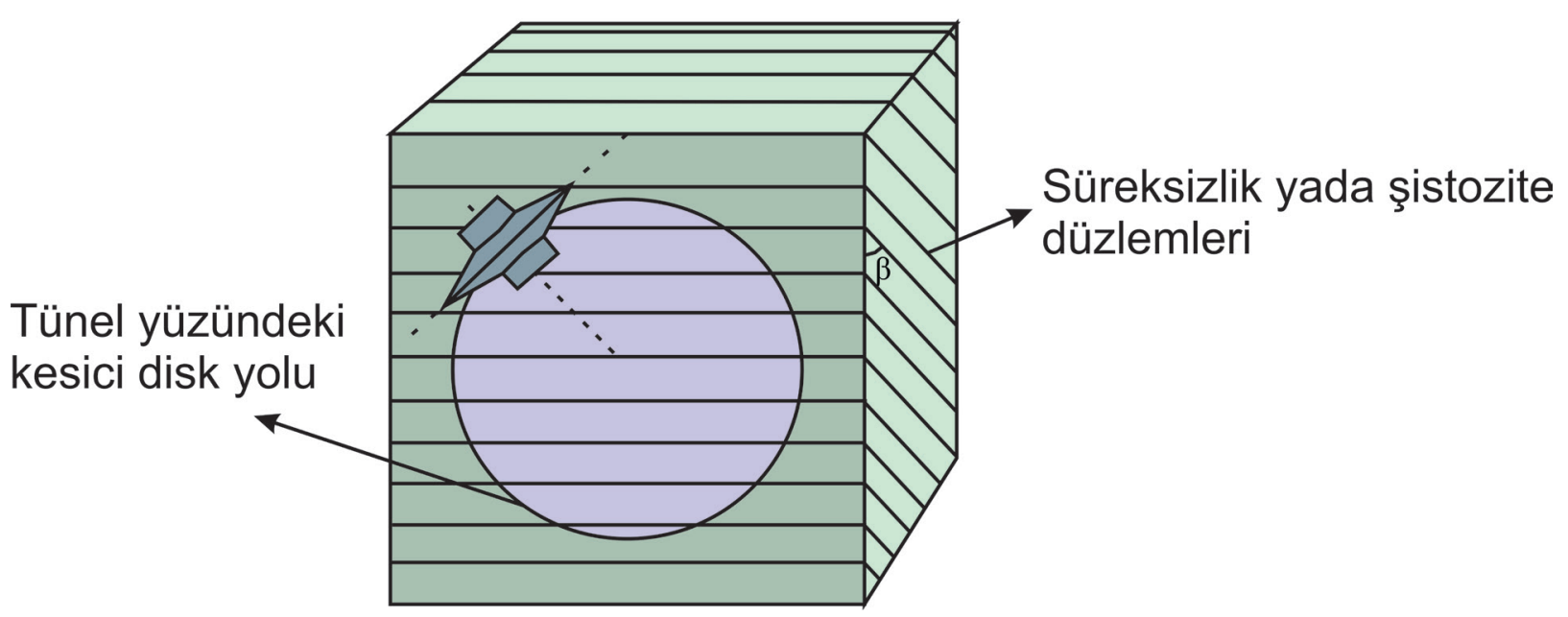

Şekil 2. Süreksizlik düzlemleri ve TBM konumu arasındaki açı ( $\beta$ ) (Sanino, 1985).

Figure 2. The angle between the discontinuity planes and the TBM position ( $\beta$ ) (Sanino, 1985). 
Poşluk, Korkanç

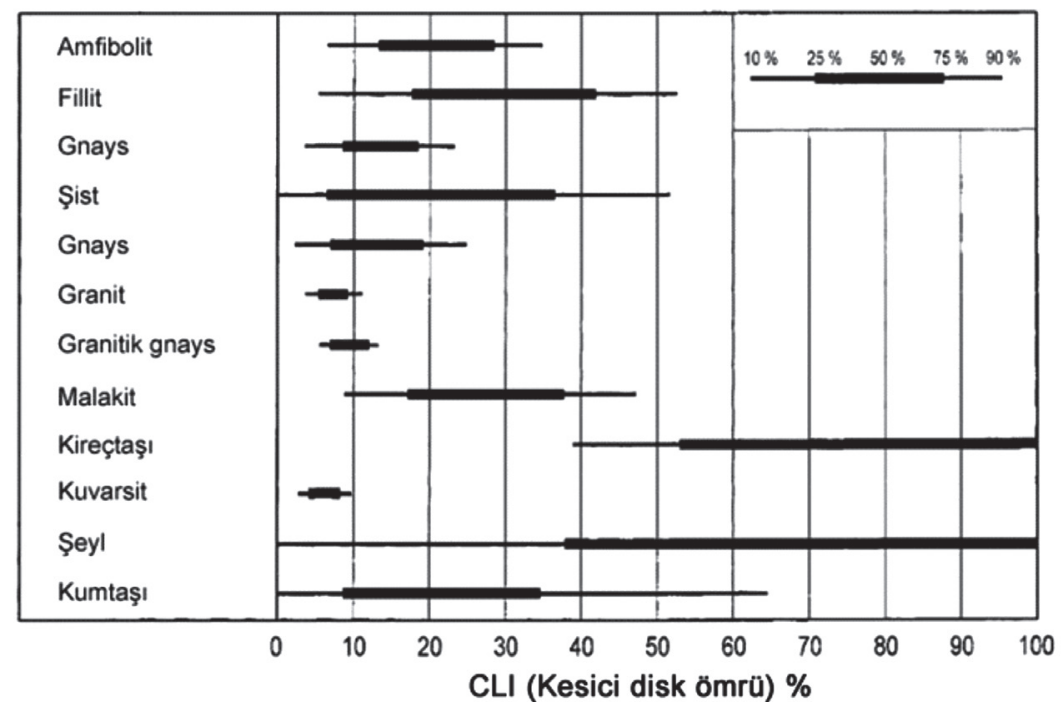

Şekil 3. Kesici ömrü tahmin abağ1 (Movinkel ve Johannessen, 1986).

Figure 3. Cutter life estimation chart (Movinkel and Johannessen, 1986).

q (Kuvars minerali yüzdesi), kayaçta bulunan kuvars minerallerinin modal analiz ile bulunan yüzdelik değeri olarak ifade edilmektedir. $\sigma_{\theta}$ (iki eksenli gerilme), farklı şiddetteki iki asal normal gerilmenin $\left(\sigma_{1}>\sigma_{3}\right)$ etkisinde kalan cisimde 'iki eksenli gerilme' durumu oluşur (Yüzer ve Vardar, 1986). Bu gerilme durumunu da Mohr diyagramında bir daire ile göstermek mümkündür. $\mathrm{Bu}$ dairenin eşitliği tek eksenli gerilme durumuna benzer şekildedir (Yüzer ve Vardar, 1986).

En büyük asal normal gerilme $\left(\sigma_{1}\right)$ ile $\beta$ açısı yapan herhangi bir yüzey üzerine etkiyen normal $\left(\sigma_{N}\right)$ ve teğetsel $\left(\tau_{N}\right)$ gerilmelerin şiddetleri, bu bilinen $\sigma_{1}$ ve $\sigma_{3}$ göre;

$$
\begin{aligned}
& \sigma \theta=\left(\frac{\sigma 1+\sigma 3}{2}\right)-\left(\frac{\sigma 1-\sigma 3}{2}\right) \cos 2 \beta, \\
& \tau \theta=\frac{1}{2}(\sigma 1-\sigma 3) \sin 2 \beta
\end{aligned}
$$

eşitliğinden bulunmuştur (Yüzer ve Vardar, 1986).
Bu eşitlik, düzlemsel gerilme durumu için Mohr-Columb analizlerinden elde edilir.

\section{Kaya Kütle Çalışmaları}

Sondaj çalışmalarından elde edilen 65 adet numune üzerinde, ISRM (2007) belirtilen yöntemler esas alınarak laboratuvar deneyleri gerçekleştirilmiştir. $\mathrm{Bu}$ deneyler ile kayaçların birim hacim ağırlık, tek eksenli basınç direnci, Poisson oranı ve elastisite modülü değerleri belirlenerek derinlik ile ilişkilendirmek amacı ile grafikler oluşturulmuştur.

\section{BULGULAR}

\section{Tünel Güzergâhının Jeolojik Özellikleri}

Tünel güzergâh1 boyunca Sögüt metamorfiklerine ait olan yeşil şist fasiyesinde metamorfizma geçirmiş, çoğunlukla ince taneli kayaçlardan oluşan kayaç gurupları yer almaktadır. Ayrıca bu kayaçları kesen felsik 
sokulumlar bulunmaktadır. $\mathrm{Bu}$ sokulumlar dağınık yapıdadır. Söğüt metamorfikleri tünel güzergâhında meta-pellitler ve meta-bazitler olarak iki grupta incelenebilirler. Metamorfik kayaçları uyumsuz olarak örten Neojen çökelleri (Miyosen karasal çökelleri, yamaç molozu, alüvyonlar ve heyelan malzemesi) ise üst kotlarda yer almakta ve tünel seviyesinde gözlenmektedir. Ayrıca tünel güzergahı boyunca, tüneldeki aşırı kazıya bağlı olarak 3 adet obruk oluşmuştur ve bu obruklar topografik yöntemler ile kayıt altına alınmıştır (Şekil 4 ve Şekil 8).

Tünel güzergahı boyunca karşılaşılan temel birim Şentürk ve Karaköse (1981) tarafindan Söğ̈̈t Metamorfitleri, Yılmaz (1979) tarafindan da Söğüt Meta-baziti olarak adlandırılmıştır. Bu kayalar çoğunlukla meta-pellit ve meta-bazit (serpantinit, serpantinleşmiş peridotit, piroksenit, ve diyabaz-mikrogabro) kayalardır.
Meta-pellitler (Şekil 5-a) tünel güzergâhında oldukça geniş bir alan kaplamaktadır. Yaygın olarak gri fillatlar ve bunlarla ardalanmalı olan grimsi-boz renkli meta-kumtaşları ve metasilttaşlarından oluşmaktadır (Şekil 5-b). Fillatlar s1k aralıklı yapraklanmalıdır. Genel olarak hakim yapraklanma yönü kuzeye doğrudur, ancak s1k kıvrımlanma ve faylanma nedeni ile yersel olarak farklı1ıklar görülmektedir. Yapraklanma yüzeyleri parlaktır. Tane boyunun nispeten irileştiği kesimlerde benekli şist görünümü kazanmışlardır. Kırık ve makaslamalarında kolaylıkla ezildiğinden yumuşak ve dağılmış halde görünürler. Bu tür makaslanma ve ezik kesimleri mekanik ufalanma nedeniyle siyahımsı bir renk kazanmakta ve bu nedenle grafitik şiste benzemektedir (Tüysüz ve Genç, 2012; Mahmutoğlu vd., 2006). Fillatlar farklı kalınlık ve şekilde kuvars ara seviyeleri içermektedir.
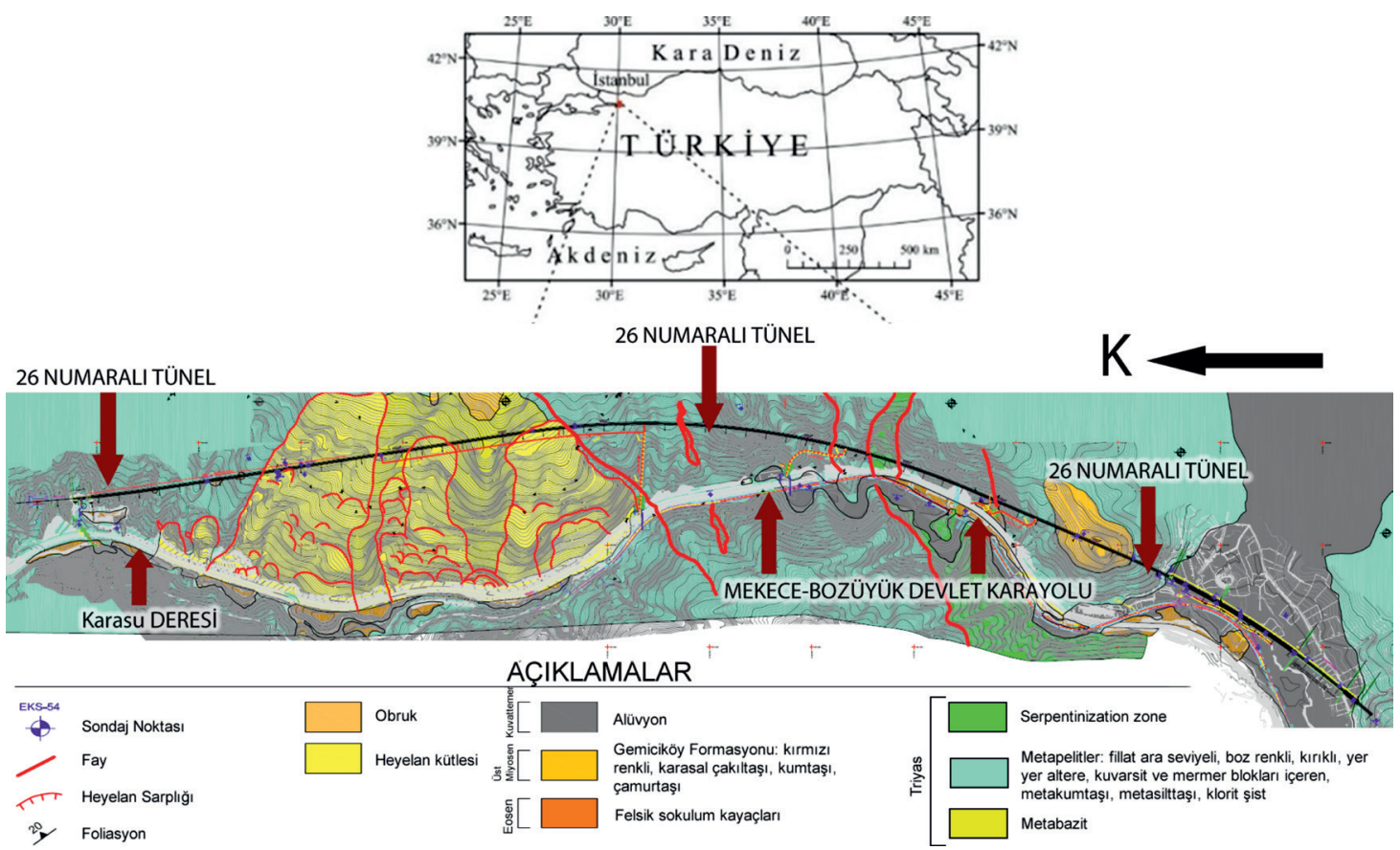

Şekil 4. 26 numaralı tünelin yer bulduru ve genel jeoloji haritası.

Figure 4. Location and general geological map of the Tunnel 26. 
$\mathrm{Bu}$ seviyeler 1cm'den 30-40 cm kalınlığa kadar değişen bantlar şeklindedir. Kalın kuvars damarlarının muhtemelen tektonik deformasyon nedeniyle kopup budinler halinde kaya kütlesi içerisinde dağılması ile bağımsız ve kalın kuvars blokları oluşmuştur (Tüysüz ve Genç, 2012). Bu kayaların petrografik özelliklerine bakıldığında, genellikle kataklastik doku sergiledikleri görülmektedir (Şekil 6a).
Söğüt metamorfikleri içerisinde yer alan meta-bazitler bazik kökenli lav ya da piroksenlerin metamorfizması sonucunda oluşmuşlardır. Metabazitler genellikle yeşil ve tonlarındaki renklerde mostra vermektedir. Yer yer masif, çoğunlukla yapraklanmalıdır (Şekil $5 \mathrm{c})$. İnce kesitlerinde şistik ve porfiroblastik dokularıyla belirgindirler (Tüysüz ve Genç, 2012) (Şekil 6b). Bazı kesimlerinde açık ve
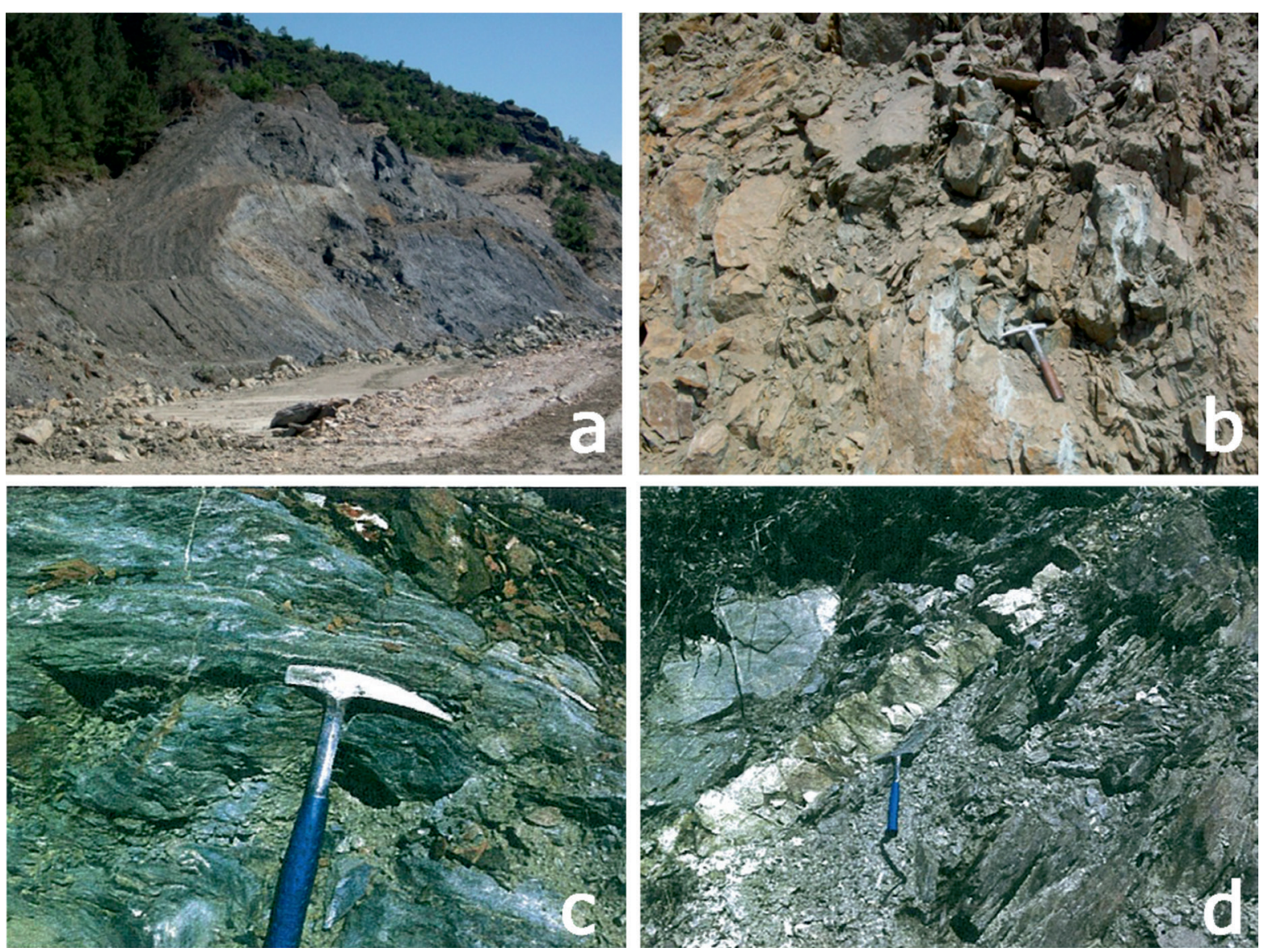

Şekil 5. Söğüt metamorfitleri ve onları kesen felsik intrüzyonlar (a- metapelitlerin tünel girişinde görünümü, b-fillat ve metasilttaşı, c-serpantinit içerisindeki kuvars bantları, d-felsik intrüzyonlar (Tüysüz ve Genç, 2012)).

Figure 5. Sögüt metamorphites and felsic intrusions intersecting them (a-metapelite appearance at tunnel entrance, b-phyllite and metasilestone, c-quartz bands in serpentinite, d-felsic intrusions (Tüysüz and Genç, 2012)). 
koyu yeşil renklerde bantlı yapıları vardır. Metapellitler ile iki tür dokanak ilişkileri vardır. Bunlardan ilki, Ahmetpınar Köyü kuzeyinde uyumlu, diğeri ise, Ahmetpınarı Köyü güneyinde Çırçır Dere vadisi içerisindeki faylı dokanaktır. Meta-bazitler metapellitlere oranla daha masif, daha az bozunmuş ve dayanımları daha yüksektir. Genellikle az-orta bozunmuş ve zayıf kaya özelliği göstermektedir.

Felsik intrüzyonlar, aşırı ayrışmalı, silisleşmiş, felsik bileşimli dayk, sil, damar ve stoklardan oluşmaktadır. Mostrada beyaz, kirli beyaz, sarıms1 ve yer yer kahverengi renklerde gözlenirler. Dayk ve sil kalınlıkları birkaç cm ile 3-5 m arasında değişim göstermektedir (Şekil $4 d)$.
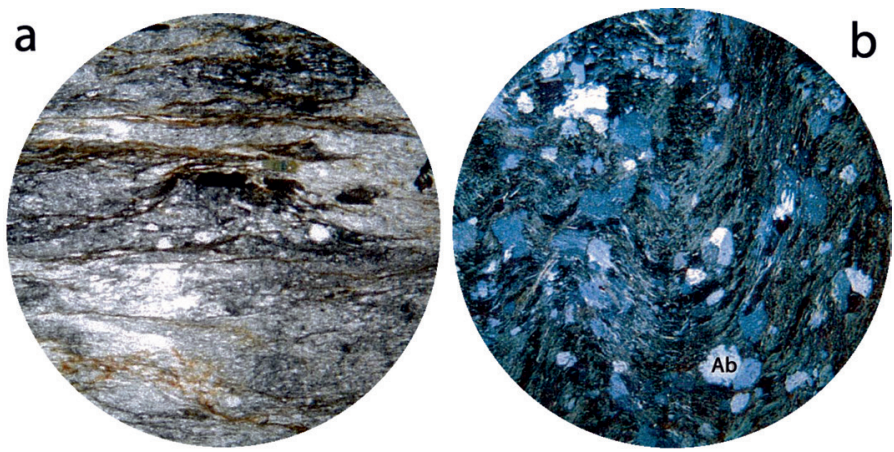

Şekil 6. a) Fillatlarda kataklastik doku, b) Porfiroblastik ve mikro kıvrımlı dokulu metabazit (Porfiroblastlar albitlerden (Ab) oluşmaktadır) (Tüysüz ve Genç, 2012).

Figure 6. a) Cataclastic texture in phyllites, b) Porphyroblastic and microfold textured metabasites (Porphyroblasts consist of albites (Ab)) (Tüysüz and Genç, 2012).

Neojen yaşlı çökel kayalarıinceleme alanında Ahmetpınarı Köyü D-GD'sunda Çiftçeşme ve Tekçeşme tepeleri arasındaki zirvelerde mostra vermektedir. Tünel güzergâhının güneyinde (tünelin çıkış kısmında) ise K-G yönünde akan Karasu Çayı vadisi boyunca oluşmuş alüvyonlar yeralmaktadır. Söz konusu alüvyonlar, bölgedeki tüm kaya birimlerinin çakıl, kum, kil boyutlarındaki tutturulmamış malzemelerinden oluşmaktadır. Ayrıca Ahmetpınar Köyü'nün batısında oldukça geniş bir alanda toplanmış her boy malzemeden oluşan heyelan malzemesi de gözlenmektedir (Şekil 1). Tünelin açılan kısmında birimlerle karşılaşılmamıştır.

\section{Mühendislik Jeolojisi Çalışmaları}

Tünel açma makinesinin çalışmaya başladığ 1 tünel girişinden makinenin sıkıştığı noktaya kadar olan bölgeyi incelediğimiz bu bölümde 26 numaralı tünel güzergahı, jeolojik açıdan oldukça karmaşık yapılar barındırmaktadır. Tünel güzergâhının giriş kısımlarında (Ahmetpınar Köyü batısında) heyelan, devamında fay zonları, zayıf-çok zayıf kayalar ve bu kayaların içerisinde kuvars budin ve blokları yer almaktadır. Ayrıca 
Poşluk, Korkanç

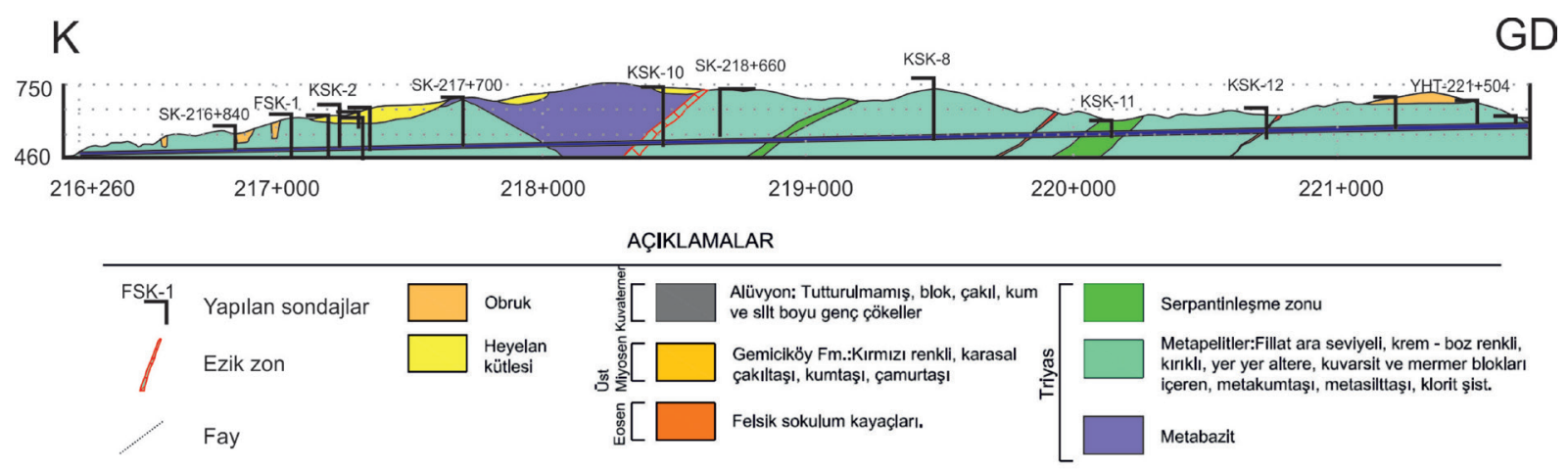

Şekil 7. İncelenen 26 numaralı tünelin boy kesiti (Tüysüz ve Genç, 2012'den değiştirilerek) (Tünel güzergahı kuzeyden başlayarak geniş bir kurp ile K-G-GB-GD yönlerini kat etmektedir).

Figure 7. Size cross-section of Tunnel 26 (modified from Tüysüz and Genç, 2012) (Tunnel route starting from the north by a wide curve and continuing in the N-S-SW SE directions).

Sondajlardan elde edilen dayanım ve deformobilite değerleri oldukça değişken bir aralıkta yer almaktadır (Şekil 8). Özellikle sondajlardan alınan örneklerin tünel kotlarına karşılık gelen verileri kullanılarak yapılan değerlendirmelerde, derinlikle kesilen birimlerin mühendislik özellikleri nispeten değişkenlikler sunmaktadır. Genel olarak güzergâhta farklı kesimlerde yapılan sondajlarda kesilen birimlerde daha derinden alınan örneklerin mühendislik özellikleri de değişkendir (Şekil 8). $\mathrm{Bu}$ da birimdeki anizotropinin (inhomojenite) bir göstergesi olarak değerlendirilmiştir. $\mathrm{Bu}$ deneylere ek olarak kayaların içsel sürtünme parametrelerinin belirlenmesi amaciyla 8 adet üç eksenli basınç deneyi yapılmıştır. Bu deneylerden elde edilen sonuçlara göre metapellitlerde ortalama $4.65 \mathrm{MPa}$ kohezyon ve $40.5^{\circ}$ içsel sürtünme açısı gibi oldukça yüksek direnç parametreleri elde edilmiştir.

\section{$Q_{\text {твм }}$ Yöntemi ile TBM Performans Analizi}

$\mathrm{Q}_{\mathrm{TBM}}$ yöntemi ile performans analizi 26 numaralı tünelin girişinden, TBM'in sıkıştığ noktaya kadar olan (1250 metre) bölgede yapılmıştır. 1250 metrelik bu kısım tünel üzeri örtü kalınlığı, birimlerin kendi içlerindeki farklılıkları ve birim değişikliklerine göre 4 bölgeye ayrılmıştır (Şekil 9).

Öncelikle ayrılan her bölge için yönlendirilmiş $\mathrm{RQD}_{\mathrm{o}}$ ile $\mathrm{Q}$ değeri saptanmıştır (Çizelge 2). Daha sonra aşınmadan dolayı ilerleme azaltma faktörü başlangıç değerleri $\left(\mathrm{m}_{1}\right)$ Şekil 1 yardımıyla bulunmuş ve yine her bölge için ayrı ayr1 kaya kütlesi dayanım (SIGMA) değerleri hesaplanmıştır (Tablo 3). Hesaplamalar sırasında kullanılan birim hacim ağırlık, tek eksenli basınç ve porozite değerleri laboratuvar deneylerinden elde edilen verilere göre alınmıştır. Her bir kesiciye gelen itme kuvveti değeri üretici firma abaklarından belirlenmiştir. Ayrıca geçilecek olan birimdeki kuvars yüzdesi, Tüysüz ve Genç (2012) tarafından yapılan çalışmadan alınmıştır. 


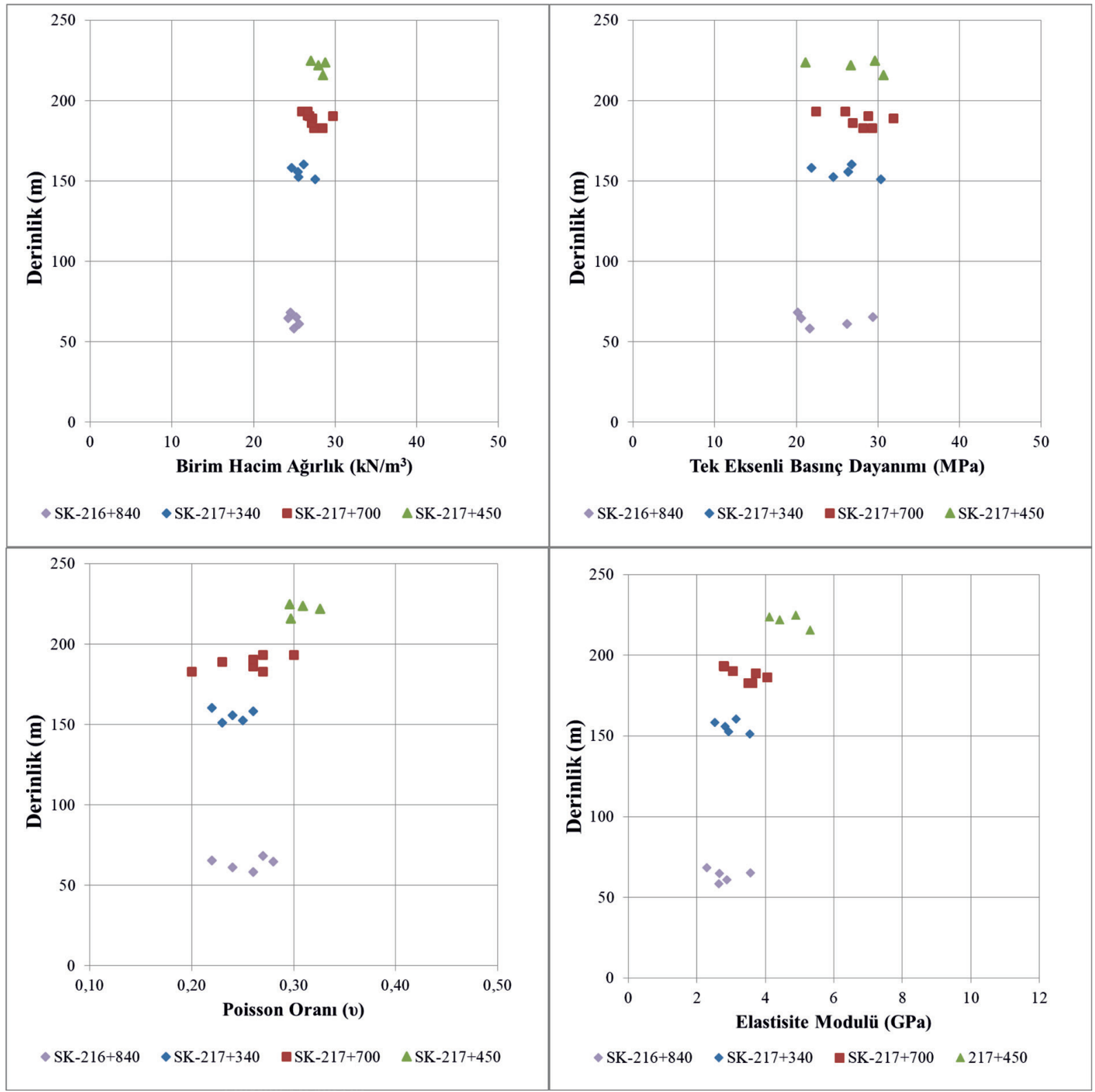

Şekil 8. Elde edilen deney sonuçlarının derinlikle değişimi.

Figure 8. Variations of the test results according to depth. 


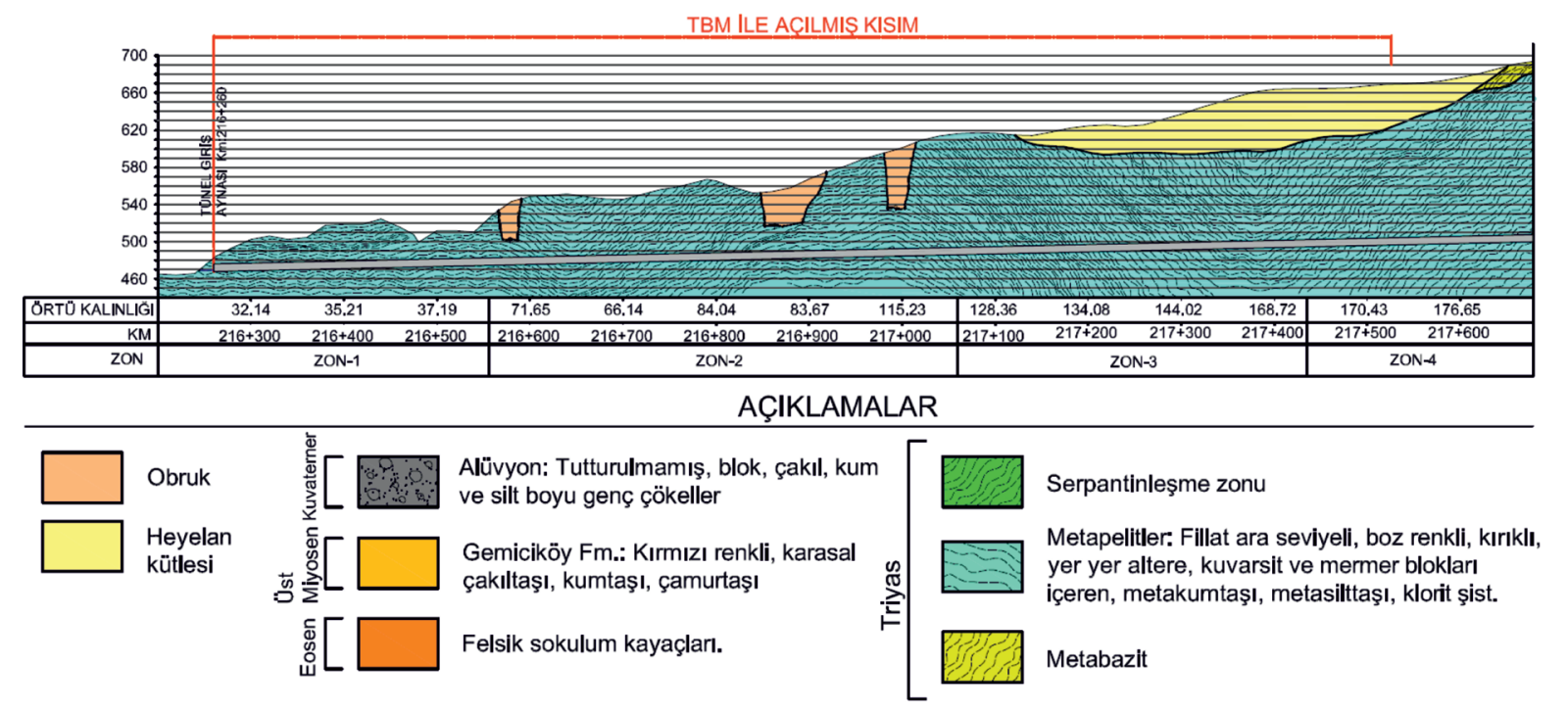

Şekil 9. Tünelin TBM ile açılan bölge ve bölümleri.

Figure 9. Zone and sections of tunnel opened by TBM.

Çizelge 2. Bölgeler için Q-sistemi hesaplamaları.

Table 2. Q-system calculations for sections.

\begin{tabular}{cccccccc}
\hline Bölge No & RQDo & Jn & Jr & Ja & Jw & SRF & Q \\
\hline $\mathbf{1}$ & 20 & 9 & 0.5 & 1 & 0.66 & 10 & 0.073 \\
$\mathbf{2}$ & 30 & 9 & 1 & 1 & 0.66 & 2.5 & 0.88 \\
$\mathbf{3}$ & 40 & 9 & 1 & 1 & 0.66 & 5 & 0.587 \\
$\mathbf{4}$ & 40 & 9 & 1 & 1 & 1 & 2.5 & 1.778 \\
\hline
\end{tabular}

Çizelge 3. Bölgeler için $\mathrm{Q}_{\text {твм }}$ hesabı.

Table 3. QTBM calculation for sections.

\begin{tabular}{|c|c|c|c|c|c|c|c|c|c|c|c|c|c|c|c|}
\hline $\begin{array}{c}\text { Bölge } \\
\text { No }\end{array}$ & $\gamma$ & $\sigma_{\mathrm{c}}$ & Qc & SIGMA & $\mathrm{m}_{1}$ & F & CLI & $\begin{array}{c}\text { q (kuvars } \\
\text { mineral } \\
\text { oranı \%) }\end{array}$ & $\sigma_{\theta}$ & $\mathbf{Q}_{\text {TBM }}$ & D (m) & n (\%) & $\mathbf{m}$ & $\begin{array}{c}\mathrm{PR}(\mathrm{m} / \\
\text { saat) }\end{array}$ & $\mathrm{AR}$ (m/saat) \\
\hline 1 & 2.23 & 10 & 0.0073 & 2.1663 & -0.45 & 25 & 30 & 45 & 3 & 0.0008 & 13.77 & 10 & -0.62 & 20.99 & 0.27 \\
\hline 2 & 2.52 & 20 & 0.176 & 7.0611 & -0.23 & 25 & 30 & 50 & 13.66 & 0.1519 & 13.77 & 5 & -0.3 & 7.29 & 1.14 \\
\hline 3 & 2.72 & 28 & 0.1643 & 7.4483 & -0.25 & 25 & 30 & 50 & 7.3 & 0.0571 & 13.77 & 5 & -0.33 & 8.86 & 1,4 \\
\hline 4 & 2.67 & 32 & 0.5689 & 11.0617 & -0.17 & 25 & 30 & 50 & 5 & 0.176 & 13.77 & 5 & -0.22 & 7.08 & 3.56 \\
\hline
\end{tabular}


Yapılan değerlendirmelere göre, 1 nolu bölge en kötü kaya koşullarını, 4 nolu bölge ise incelenen bölgeler arasinda nispeten daha iyi koşulları göstermektedir. Bu durum ortamın anizotropisi ile ilerleme hızı arasındaki etkileşimi belirgin olarak ortaya koymaktadır. Yapılan hesaplamalar sonucunda, $\mathrm{Q}_{\mathrm{TBM}}$ yöntemi ile 26 numaralı tünel için TBM performansı analizine göre 1250 metrelik tünelin açılabilmesi için 1817.7 saat gerekmektedir. Bu da günlük yaklaşık 16.5 metrelik ilerlemeye karşı1ık gelmektedir.

\section{SONUÇLAR VE ÖNERILER}

Ampirik ve deneysel çalışmalara dayanılarak geliştirilen birçok TBM performans tahmin yönteminde kullanılan girdi parametreleri, sağlam kayacın tek eksenli basınç dayanımı, süreksizlik açıklık-aralık ve yönelimi, kesici başına varsayılan itme kuvveti ve kesici kafa çapı olarak sıralanabilir. $\mathrm{Bu}$ çalışmada, $\mathrm{Q}_{\mathrm{TBM}}$ yönteminin anizotrop zayıf kaya ortamındaki uygulanışında girdi parametrelerinin doğruluğu incelenmiştir. $\mathrm{Bu}$ amaçla 26 numaralı tünelde imalat öncesi yapılan hesaplamalar ile imalatın durmasına kadar geçen süre ile sınırlı TBM performans verisi kullanılmıştır.

İmalatlar sirasinda TBM'in siklıkla duraklaması ve durması beklenilen imalat/zaman hesaplarının gerçekleşmemesine neden olmuştur (Şekil 10). $\mathrm{Q}_{\mathrm{TBM}}$ yöntemi ile yaklaşık 76 günde tamamlanacağı öngörülen kısımda çalışmalar, 22 aydan daha uzun sürmüştür. Bunun en büyük nedeni uzun durmalardır. Durmaların nedeni $\mathrm{Q}_{\mathrm{TBM}}$ yönteminde öngörüldüğü gibi kesici disk değişimi için değil, tünel destek elemanlarında yaşanan sorunlar, makine revizyonları ve kayamakine etkileşim sorunlarıdır. Dolayısıyla her durmada makine bakımıyla birlikte kesici diskler de değişmiştir. $\mathrm{Bu}$ nedenle, kesici disklerin değişim periyodu ile ilgili sağlıklı bir duraklama süresinden bahsetmek mümkün olamamıştır.

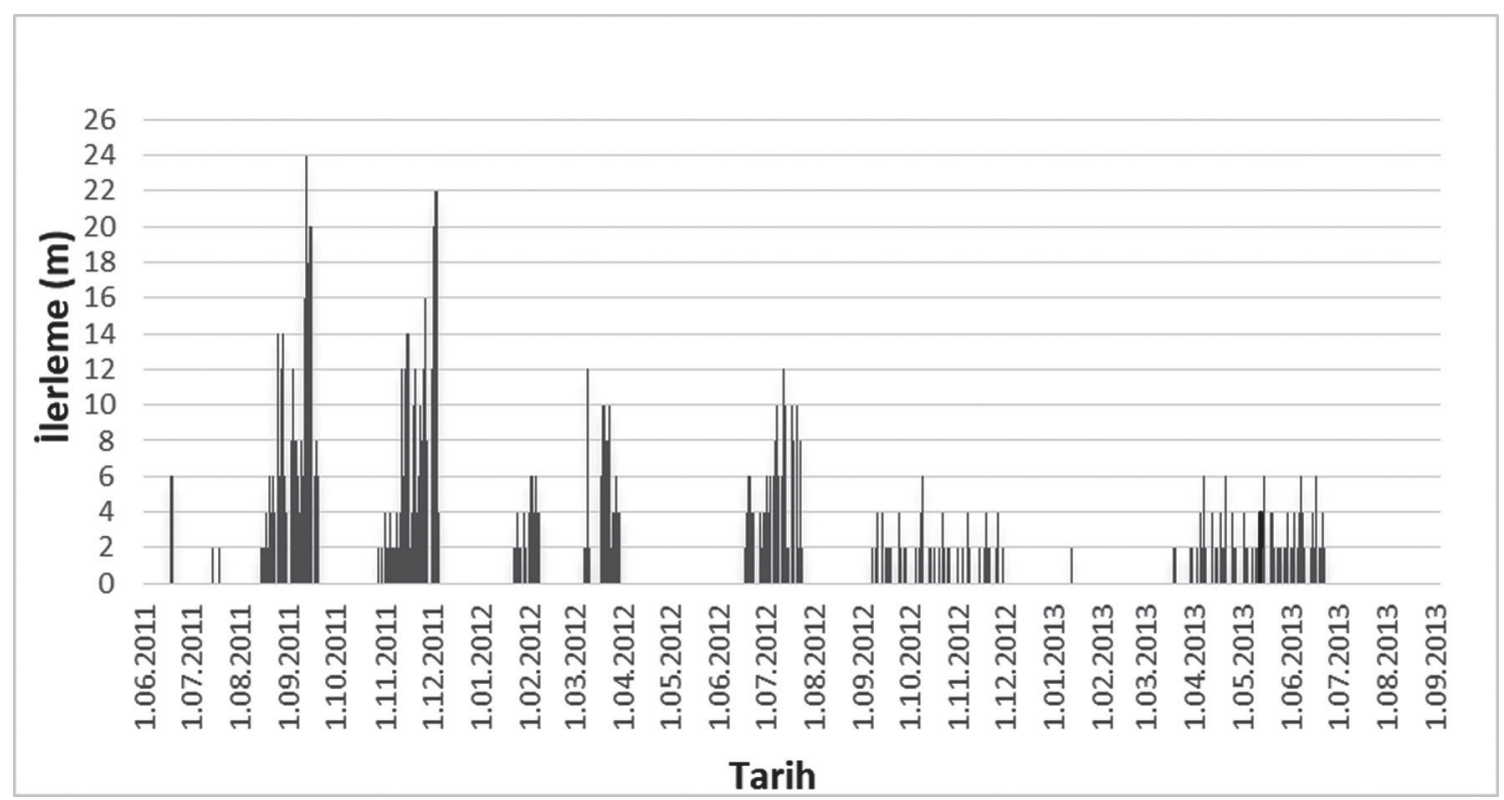

Şekil 10. TBM günlük ilerleme grafiği.

Figure 10. Daily progress of TBM. 
Makine kaynaklı sorunların yanında, metapellitlerin kuvars blok, damar ve budinler barındırması, şistozite düzlemlerinin oldukça fazla kıvrımlı olması, bu kayaların kazı sırasında ve sonrasında sorunlar oluşturmasının en büyük nedenlerinden olduğu düşünülmüştür.

Eldeki verilerle yapılan değerlendirmeye göre anizotrop, zayıf kayada, $\mathrm{Q}_{\mathrm{TBM}}$ yönteminde kurgulanan ideal kaya-makine etkileşimi, kayaç kalitesinin zayıftan sağlama doğru geçildiğinde daha gerçekçi olduğu düşünülmektedir. Yönteminin kullandığı kayanın süreksizlikleri, tek eksenli basınç dayanımı ve kesici disklerin uyguladığı kuvvet, kazma-sökme kavramları ile ilişkilidir. Oysa zayıf anizotrop kayaçlarda temel sorun, kazma-sökme değil, in-situ gerilme durumu ile geçilen ortamın direnci arasındaki oranla ilişkili zamana bağlı davranış farklılaşmasından kaynaklanmaktadır.

Bunun yanında anizotrop zayif kaya koşullarında yeni veriler ile konunun daha fazla araştırmacı tarafından ele alınması, yöntemin başarısı açısından oldukça önemlidir.

\section{KAYNAKLAR}

Barton, N. R., Lien, R., Lunde, L., 1974. Engineering classification of rock masses for the design of tunnel supports. Rock Mechanics, 6(4), 189-239.

Barton, N., 2000. TBM Tunneling in jointed and faulted rock. Balkema, Brookfield. 173 p.

Benato, A., Oreste, P., 2015. Prediction of penetration per revolution in TBM tunneling as a function of intact rock and rock mass characteristics. International Journal Rock Mechanics Mining Science, 74, 119-127.

Bieniawski, Z.T., Celada, B., Galera, J.M., 2007. TBM Excavability : prediction and machine-rock interaction. In : Proceedings, Rapid Excavation and Tunneling Conference, 1118-1130.
Bruland, A., 1998. Hard rock tunnel boring Ph.D. Thesis. Norwegian University of Science and Technology, Trondheim, Vol. 3, 54 p.

Büchi, E., 1984. Einfluss Geologischer Parameter auf die Vortriebsleistung einer Tunnelbohrmaschine. $\mathrm{PhD}$ Thesis. University of Bern, $136 \mathrm{p}$.

Delisio, A., Zhao, J., 2014. A new model for TBM performance in blocky rock conditions. Tunnelling and Underground Space Technology, 43, 440-452.

Farmer, I.W., Glossop, N.H., 1980. Mechanics of disc cutter penetration. Tunnels and Tunnelling International, 12(6), 22-25.

Frough, O., Torabi, S.R., Yagiz, S., 2015. Application of RMR for estimating rock mass-related TBM utilization and performance parameters: a case study. Rock Mechanics and Rock Engineering, 48(3), 1305-1312.

Gong, Q.M., Zhao, J., 2009. Development of a rock mass characteristics model for TBM penetration rate prediction. International Journal of Rock Mechanics and Mining Sciences, 46(1), 8-18.

Graham, P.C., 1976. Rock exploration for machine manufacturers. In: Bieniawski, Z. T. (Ed.), Exploration for Rock Engineering. Balkema, Johannesburg, 173-180.

Hassanpour, J., Rostami, J., Khamehchiyan, M., Bruland, A., 2009. Developing new equations for TBM performance prediction in carbonateargillaceous rocks: a case history of Nowsood water conveyance tunnel. Geomechanics and Geoengineering An International Journal, 4, 287-297.

Hughes, H.M., 1986. The relative cuttability of coal measures rock. Mining Science and Technology, 3, 95-109.

Innaurato, N., Mancini, R., Rondena, E., Zaninetti, A., 1991. Forcasting and effective TBM performance in a rapid excavation of a tunnel in Italy. In: Wittke W, editor. Proceedings of the 7th International Congress Rock Mechanics, 10091014. 
ISRM, 2007. The Complete ISRM Suggested Methods for Rock Characterization. Testing and Monitoring : 1974-2006, Suggested Methods prepared by the Commission on Testing Methods, ISRM, R. Ulusay and A. Hudson (eds.), Kozan Ofset, Ankara, 628 p.

Mahmutoğlu, Y., Vardar, M., Koçak, C., Şans, G., 2006. Tunnelling difficulties under squeezing and flowing conditions at Ayaş, Central Turkey. Felsbau Rock and Soil Engineering, 24(5), 4450.

Maidl, B., Schmid, L., Ritz, W., Herrenknecht, M., 2008. Hardrock Tunnel Boring Machines, Gmbh \& Co.KG, Berlin. 356 p.

Movinkel, T., Johannessen, O., 1986. Geological parameters for hard rock tunnel boring. Tunnels \& Tunnelling International, 18(4), 45-48.

Nelson, P., 1993. TBM Performance analysis with reference to rock properties, mechanized excavation. In : J.A. Hudson (ed). Comprehensive Rock Engineering, 4, 261-291.

Ozdemir, L., Miller, R.J., Wang, F.D., 1977. Mechanical tunnel boring prediction and machine design. NSF APR73-07776-A03. Colorado School of Mines, Golden, Colorado, USA. 313 p.

Palmström, A., 1995. RMI-a rock mass characterization system for rock engineering purposes. Ph.D. Thesis, University of Oslo, 400 p.

Rostami, J., Ozdemir, L., 1993. A new model for performance perdiction of hard rock TBMs. In: RETC proceedings, p. 793-809.

Rostami, J., Ozdemir, L., Nilsen, B., 1996. Comparison between CSM and NTH hard rock TBM performance prediction models. In: Proceedings, The Annual Conference of the Institution of Shaft Drilling Technology (ISDT), Las Vegas.
Roxborough, F.F., Phillips, H.R., 1975. Rock excavation by disc cutter. International Journal of Rock Mechanics and Mining Sciences \& Geomechanics Abstracts, 12, 361-366.

Salimi, A., Faradonbeh, R. S., Monjezi, M., Moormann, C., 2016. TBM performance estimation using a classification and regression tree (CART) technique. Bulletin of Engineering Geology and the Environment, 77(1), 429-440. https://doi.org/10.1007/s10064-016-0969-0

Sanio, H.P., 1985. Prediction of the performance of disc cutters in anisotropic rocks. International Journal of Rock Mechanics and Mining Sciences and Geomechanics Abstracts, 22 (3), 153-161.

Sapigni, M., Berti, M., Behtaz, E., Busillo, A., Cardone, G., 2002. TBM performance estimation using rock mass classification. International Journal of Rock Mechanics and Mining Sciences, 39, 771788.

Sato, K., Gong, F., Itakura, K., 1991. Prediction of disc cutter performance using a circular rock cutting ring. In: Proceedings, The First International Mine Mechanization and Automation Symposium, Colorado School of Mines, Golden, Colorado, USA. 23-37.

Snowdon, R.A., Ryley, M.D., Temporal, J., 1982. A study of disc cutting in selected British rocks. International Journal of Rock Mechanics and Mining Sciences and Geomechanics Abstracts, 19, 107-121.

Şentürk, K., Karaköse, C., 1981. Orta Sakarya bölgesinde Liyas öncesi ofiyolitlerinin ve mavi şistlerinin oluşumu ve yerleşmesi. Türkiye Jeoloji Kurumu Bülteni, 24(1), 1-11.

Tarkov, P.J., 1973. Predicting TBM penetration rates in selected rock types. In: Proceedings, 9th Canadian Rock Mechanics Symposium, Montreal. 263-274.

Tüysüz, O., Genç, Ş. C., 2012. TCDD Ankaraİstanbul hızlı tren projesi Vezirhan-İnönü etabı T26 tünel güzergahının jeolojisi raporu. Avrasya Yer Bilimleri Enstitüsü, İTÜ, İstanbul. 24 s. 
Poşluk, Korkanç

Yağız, S., 2002. Development of rock fracture and brittleness indices to quantify the effects of rock mass features and toughness in the CSM Model basic penetration for hard rock tunneling machines. Ph.D. Thesis, Department of Mining and Earth Systems Engineering, Colorado School of Mines, Golden, Colorado, USA, p. 289 (unpublished).
Yağız, S., 2008. Utilizing rock mass properties for predicting TBM performance in hard rock condition. Tunnelling and Underground Space Technology, 23 (3), 326-339.

Yılmaz, Y., 1979. Sögüt-Bilecik bölgesinde polimetamorfizma ve bunların jeoteknik anlamı. Türkiye Jeoloji Kurumu Bülteni, 22-1, 85-100.

Yüzer, E., Vardar, M., 1986. Kaya Mekaniği. İTÜ Vakfi Yayınları, No. 11, İTÜ Maden Fakültesi Ofset Atölyesi, İstanbul, $187 \mathrm{~s}$. 